\title{
English Teaching Platform Based on Online Education Technology and Licensure and Master's Program Technology
}

\author{
https://doi.org/10.3991/ijet.v14i16.11150 \\ Lina Wang, Ruying Huang $(\bowtie)$ \\ Beijing Jiaotong University, Huanghua, China \\ Huangry@ 163 .com
}

\begin{abstract}
This paper attempts to build a web-based English teaching platform that improves students' efficiency in English learning. After reviewing the current theories on teaching platforms, the author combined online education technology and the Licensure and Master's Program (LAMP) technology into a mixed teaching mode, which inherits the advantages of traditional teaching and network technologies. In addition, an English teaching platform was designed for the instruction and exercises for English courses. The platform is operated jointly by students, teachers and administrators. The research shows that the English teaching system, through the integration between information technology and LAMP, could be turned into a resource module to be used as a plug-in for online education; the proposed English teaching platform is a new-generation system for the teaching and learning of English reading, grammar, speaking and listening. The proposed platform greatly improves the teaching methods and the learning efficiency, laying a theoretical basis for the construction of the new teaching system platform.
\end{abstract}

Keywords - Online education, licensure and master's program (LAMP), English teaching platform, teaching design

\section{Introduction}

With the development of information technology and the Internet, people's living, learning, working and social exchanges have undergone great changes [1-2]. English is one of the most widely used languages in the world. In today's society where information technology is developing rapidly, the requirements for the English level of social members, especially the new generation of students, are increasing gradually, so that individuals can better conform to the trend of social development, meet the working demands, and improve their living quality and personal abilities [3-5]. The level of English is not only a means of evaluating students' foreign language performance, but also one of the important factors affecting their future personal development and employment opportunities [6-7].

With the implementation and advancement of the new curriculum reform, network information technology has begun to be applied in the education field. Information 
technology has gradually changed the teaching philosophy and teaching methods of schools and teachers [8-17]. However, the application level of network technology in English teaching is far from meeting the needs of students' learning. The online education is continuously integrated with the traditional teaching methods, and is constantly supplemented and improved in the process of interactive use, thus forming an English teaching system that is feasible in the teaching practice [18].

Most of the English teaching in current primary and secondary schools and universities is still taught by teachers using PPT or other methods as complementary. The course time for students to study a language is extremely limited. There is no effective English learning tool or assistant teaching platform for them to use after class, so they can't study the content taught by teachers in the class systematically [19-20]. Therefore, most of the schools and foreign language teaching institutions are in need of a practical English course teaching platform to assist students in English learning, so that they can improve their English level and English communication skills [21-22].

LAMP is a powerful web application program platform that has been gradually applied in the development of online teaching platforms [23]. Therefore, based on online education and LAMP technology, this paper combined the advantages of traditional teaching and network technologies, and designed and developed an English teaching platform that can be operated jointly by students, teachers and administrators. The research has important practical significance for teachers to carry out mixed teaching and improve students' English learning efficiency, and it lays a theoretical foundation for the research and development of new teaching platforms.

\section{Basic Theories of Teaching Platform}

\subsection{Online education}

Online education, also known as network teaching system or network support platform, is generally divided into Learning Management Systems (LMS) and Learning Content Management Systems (LCMS). The former is mainly to manage the administrative and academic affairs of teaching, optimize the management procedures, and improve the efficiency of teaching management. The latter is a teaching management program for teachers and students, which can help students arrange the required courses and promote the learning exchanges between students. For teachers, they can use the system to better understand the learning situation of the students.

Domestic network teaching systems are generally composed of three subsystems, namely the education administration subsystem, the teacher teaching subsystem and the student learning subsystem. The specific content includes: system management tools, new curriculum development tools, convenient communication tools, comprehensive detection functions, and systematic data management and statistics functions. This paper combined with the problems encountered by teachers and students in the actual operation process to research and develop the English teaching platform based on online education technology and the LAMP technology. 


\subsection{Online education technology}

Online education technology is a virtual teaching environment, in which teachers and students use the virtual network to teach and learn. It is an Internet-based software package with characteristics of simple operation, low cost and wide application. The Internet-based teaching platform built for teachers and students is no longer limited to the traditional face-to-face teaching method, the learning time is free, and the learning objects are limitless. In addition, the source code of the software is open, and everyone can copy and modify it, therefore, the software package is constantly upgraded, and more people's wisdom can be integrated into it. It can run not only on mainstream operating systems (Windows and Linux), but also on other operating systems. It has high security and can support international data resources such as SCORM and IMS at the same time.

\subsection{LAMP technology}

LAPMP is a very powerful web application platform that is a combination of multiple independent programs, including Linux (computer operating system), Apache (Web server), PHP (hypertext preprocessing language), MySQL (Data management system). The software developed by the LAMP combination has low cost, good performance, and strong stability, so its market share is very high. According to statistics, LAMP provides $75 \%$ of the global data access traffic.

\section{Research and Development of English Teaching Platform}

\subsection{System requirements}

The establishment of the English teaching system not only enables learning interaction during the class, but also helps students to practice and consolidate knowledge after class, moreover, it also helps teachers to prepare lessons and master the learning situation of the students. For the framework of the teaching system to be constructed, we need to start from the actual needs of teaching, and design a structural system that is easy to operate, flexible in system, and can import test questions and perform classified detection.

The system mainly includes two parts: teacher back-stage English course management and student front-stage learning, in addition, there are other users such as system administrators. In the system, students can choose the question setting method by themselves, and teachers can set the curriculum teaching type and import teaching videos or documents quickly. At the same time, the stability and operability of the system are very good, which is in line with the basic requirements of English teaching courses. 


\subsection{System function and architecture model}

Combining with the specific requirements of the English teaching system and the system requirements mentioned above, system function modules were designed as shown in Fig 1.

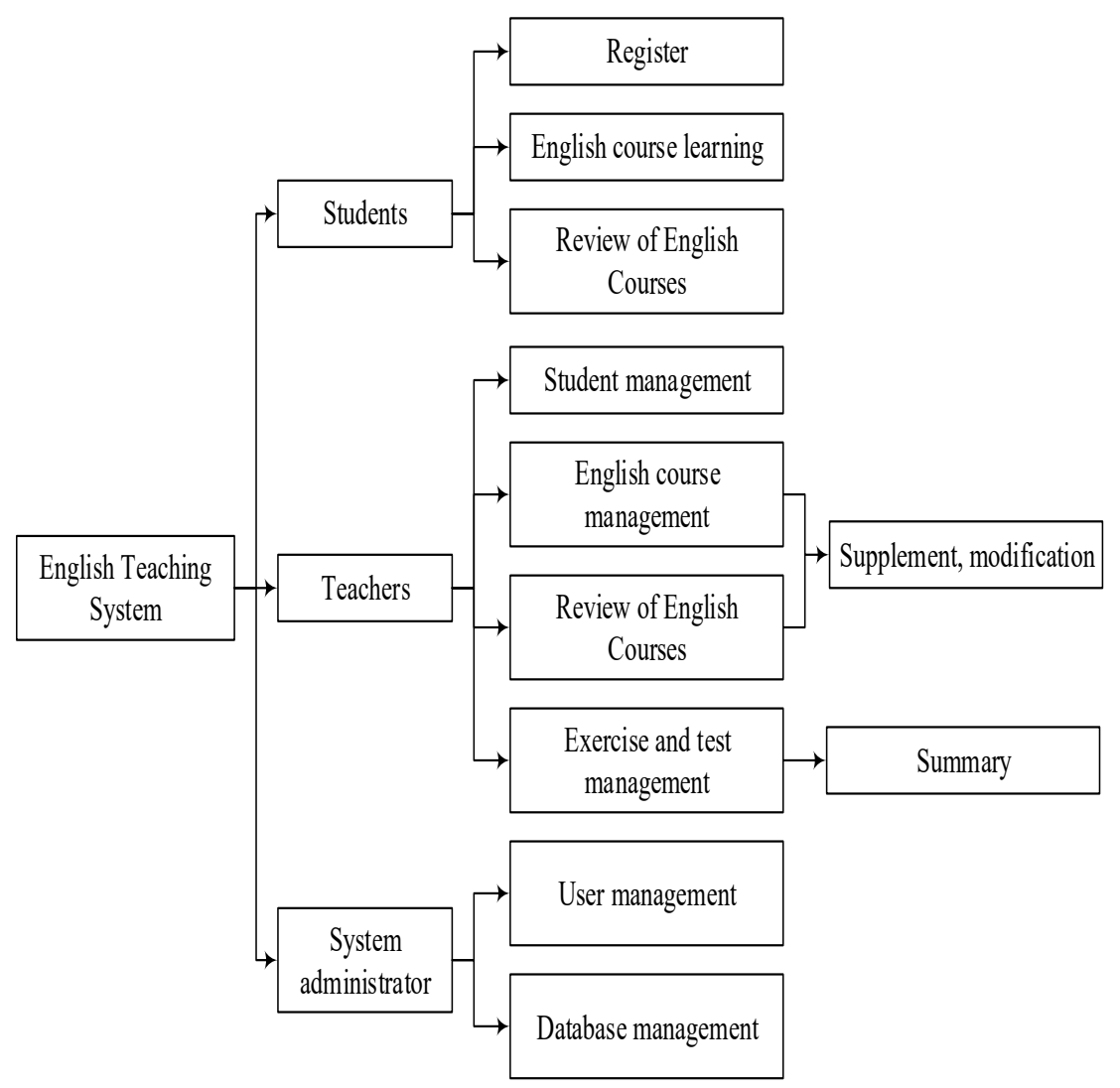

Fig. 1. System function modules

The entire English teaching system is divided into three modules, the student module, the teacher module and the system administrator module. The function of the student module is relatively simple. First, students need to register an account, fill in relevant information, and then log in to the system and enter the system to modify the relevant personal information; then they can choose the learning courses, which mainly include course videos of each learnt chapter and comprehensive exercises that can help them find their own shortcomings as soon as possible.

The content in the teacher module is more complex. Teachers not only need to manage the student name list, but also their corresponding courses, learning content, teaching videos, and the exercises question banks in the back stage. Teachers can search, create, modify, delete each module, to reduce their workload, the operations 
can be conducted in batches. In addition, if teachers make a format error in the teaching information importing process, the system would give a prompt. The English exercise questions are randomly selected from the English test question bank by the system. Teachers only need to set the scores and basic information of the test questions.

The system administrator module is mainly responsible for the management of the database and the users. The management of the database is supported by the graphical software, and the operation is very simple and fast.

The system flow is divided into the front-stage student practice flow and the backstage teacher management flow. See Fig 2 and Fig 3 for the respective function flow diagrams according to their requirements.

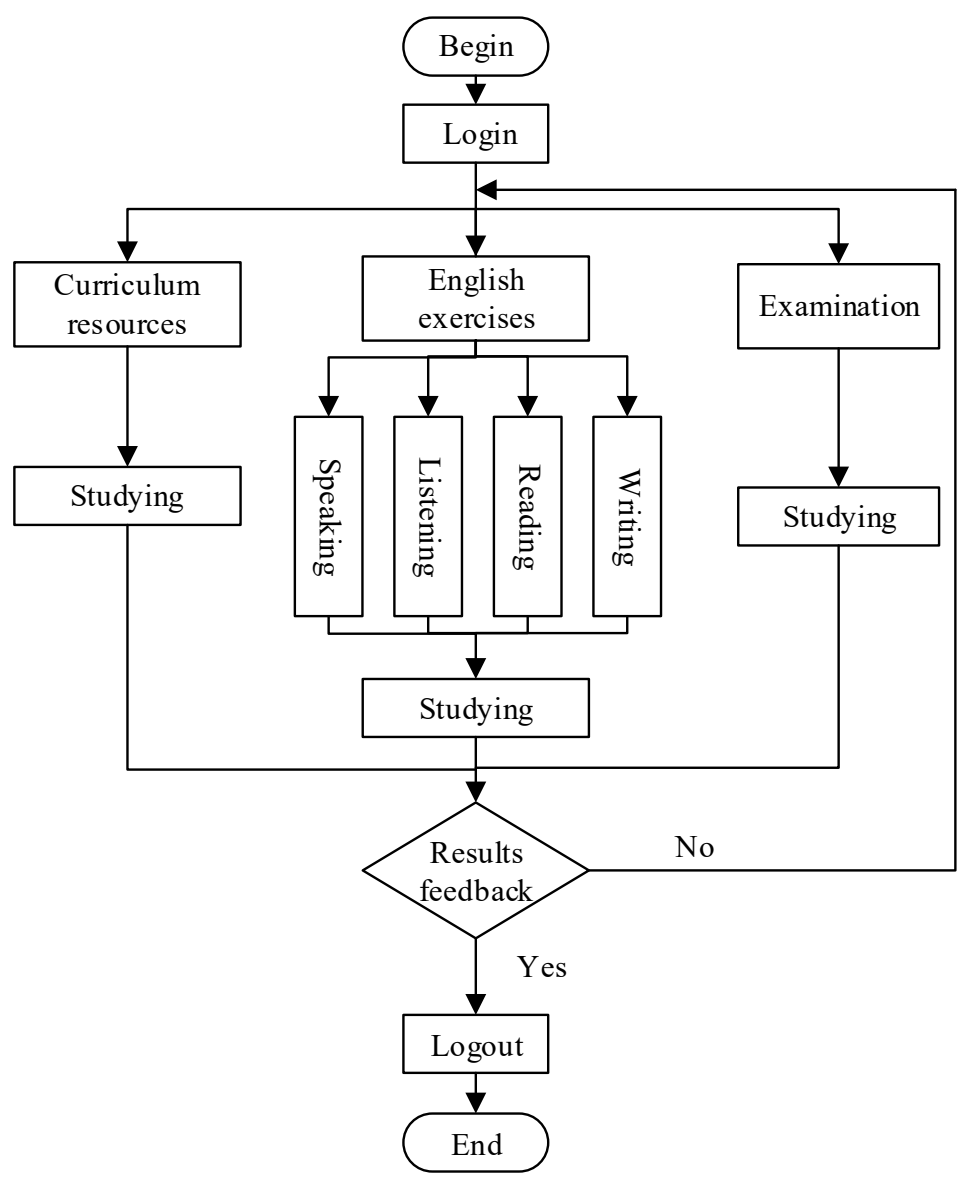

Fig. 2. Operation flow of students 


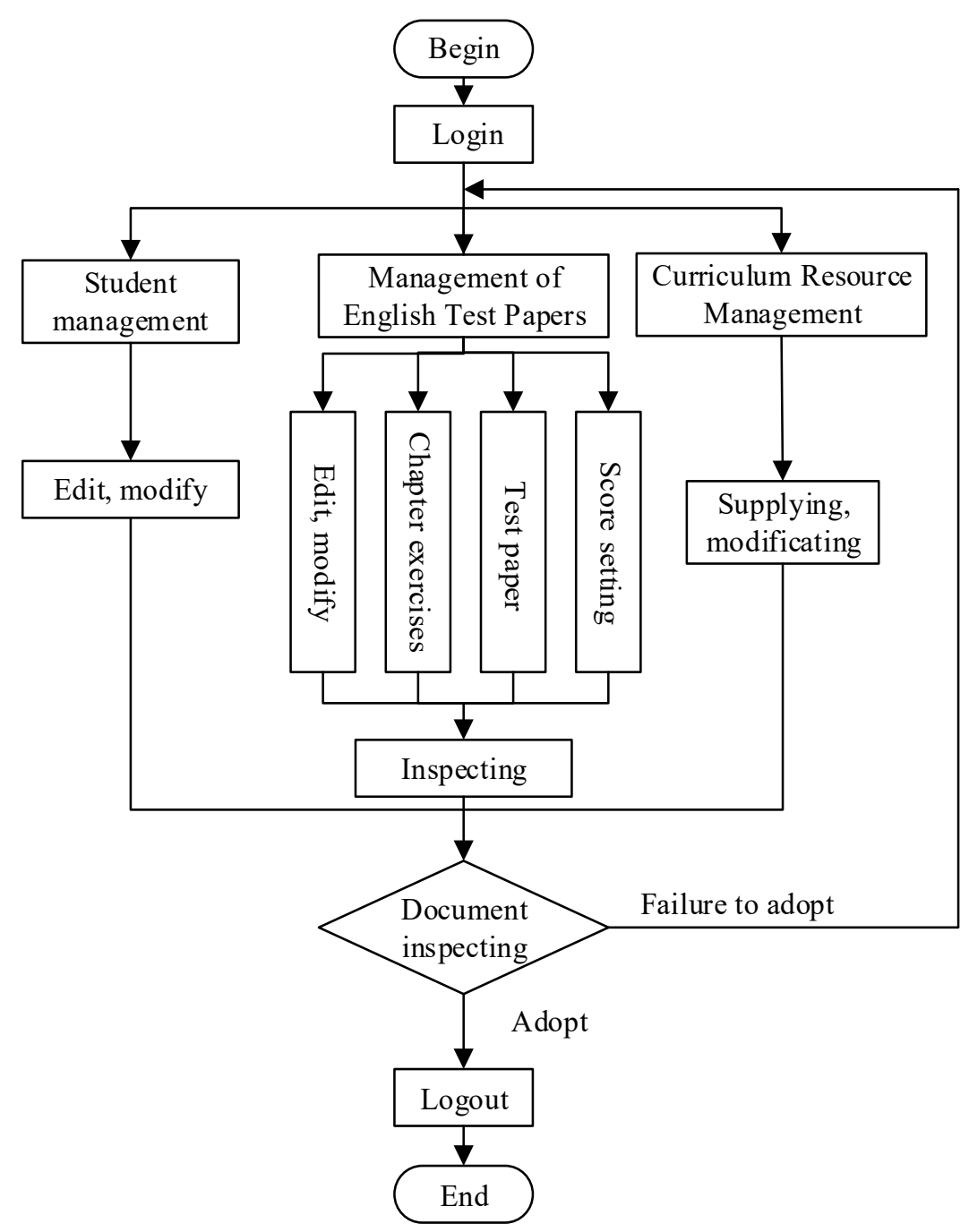

Fig. 3. Operation flow of teachers

The English teaching system was developed using technologies that combines the online education technology and the LAMP technology, its working steps are: first, the client end sends a request to the Apache server, after the server receives the request, it hands over the PHP segment program to the corresponding engine for processing and analyzing, and performs join query in MySQL database, and then the data returns to the PHP, and PHP process the data and sends it back to the Apache server, and finally displays it on the client end. 


\subsection{System platform design}

This paper combined the online education technology and the LAMP technology to develop the English teaching platform, it took the English teaching system as the resource module, programmed the interface of online education technology, and modified the development files, so that the English teaching system could be applied to the system as a plug-in of the online education technology.

The system implementation structure is shown in Fig 4. First, it processes in the data processing layer, using the corresponding data processing functions in each function module, and then, it accepts the data submitted by the transaction layer, programs the corresponding query data, and finally uses the HTML code to send it to the client end for display.

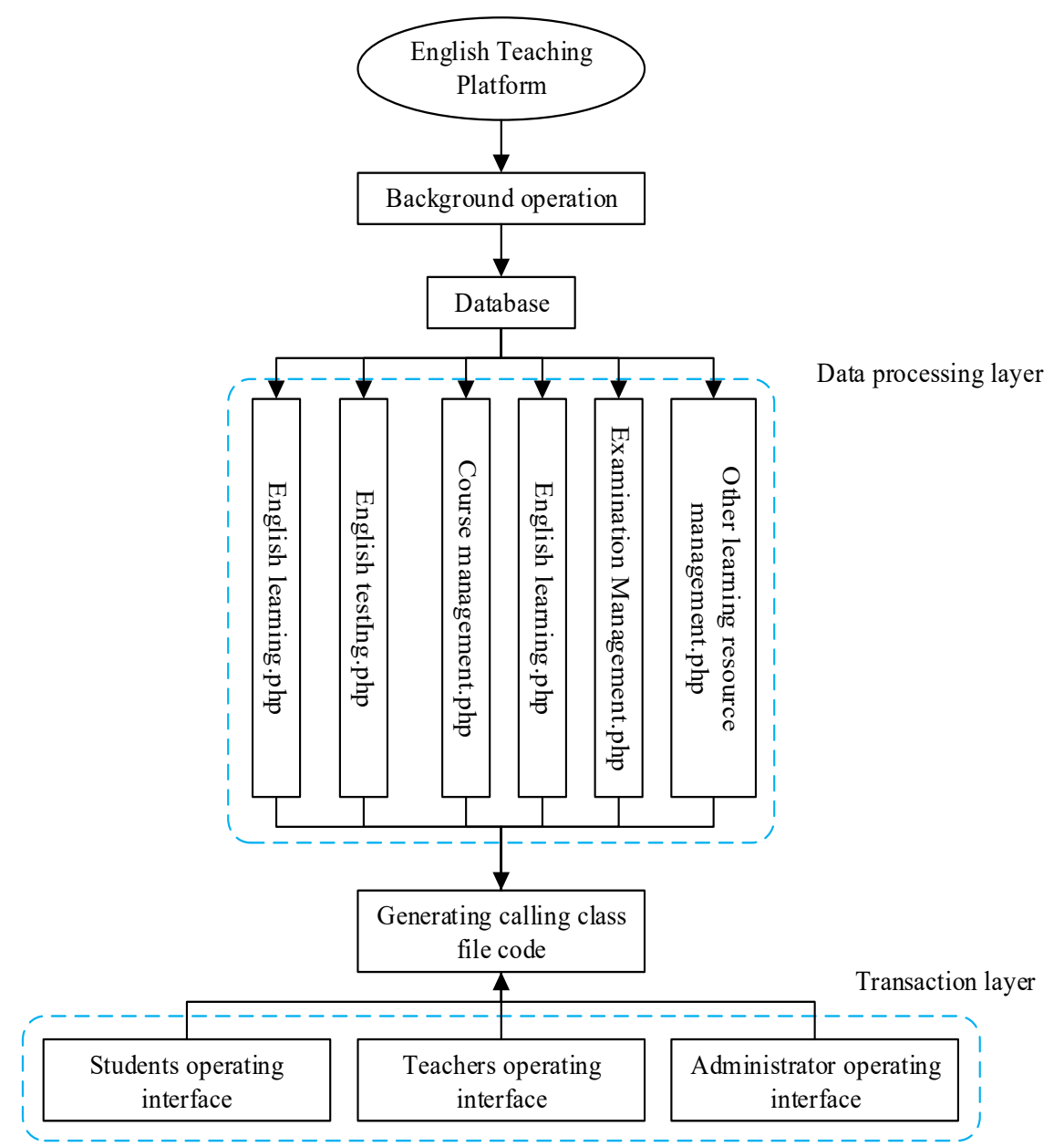

Fig. 4. System editing structural diagram 
The proposed system was jointly developed by online education technology and the LAMP technology to facilitate the introduction of resources in the English teaching platform as a module into the system. According to the development documents of online education technology, create a db folder in it and save it as a mysql. sql file. Open the server and database, enter the corresponding platform URL in the address bar, the system will automatically identify and check, and then automatically install the teaching platform into the online education platform. The student login interface is shown in Fig 5.

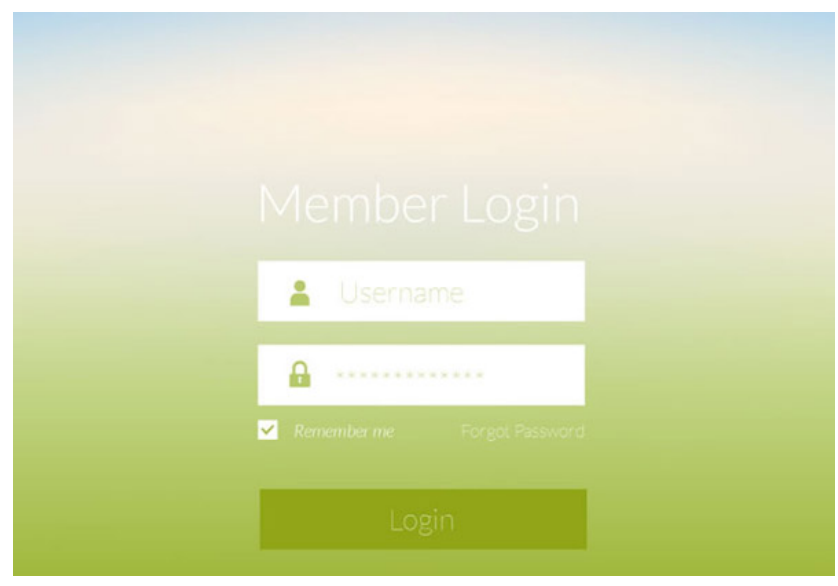

Fig. 5. Login interface

By linking the corresponding sites or files to the English teaching resource function and filling the local address of English learning course to the corresponding parameters, the system setting is completed, and then the newly developed system can be used for English teaching activities.

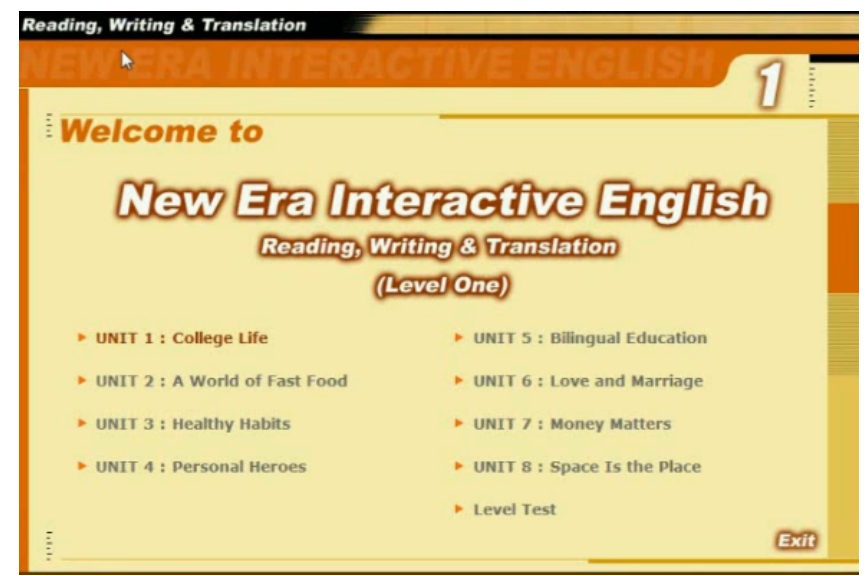

Fig. 6. Studying interface 


\section{Conclusion}

This paper studied the teaching methods and related theories of the English learning platform based on online education technology and LAMP technology, with the optimization of English course teaching methods and students' learning channels as targets, it researched and developed a new generation English teaching platform and drew the following conclusions:

- This paper integrated the online education technology and the LAMP technology, took English teaching as a resource module, programed the interface of the online education technology, and modified the development files, so that it could be used as a plug-in of the online education technology in the English teaching platform.

- This paper constructed a new generation English teaching platform for the teaching and learning of English reading, grammar, speaking and listening; The English teaching system can automatically identify the websites, and then automatically install the teaching platform into the online education platform.

- The whole English teaching platform is divided into three modules: student module, teacher module and system administrator module. The three functional modules are applicable to the operation of students, teachers and background administrators respectively to facilitate different teaching or learning activities of different groups, who can collaborate to improve the efficiency of the platform.

\section{$5 \quad$ References}

[1] Baron, J., Willis, J., Lee, R. A. (2010). Creating higher education academic and information technology resources in an international context. Computers in the Schools, 27(3): 288-308. https://doi.org/10.1080/07380569.2010.523885

[2] Yu, L., Lai, K. K., Wang, S. Y. (2006). Currency crisis forecasting with general regression neural networks. International Journal of Information Technology \& Decision Making, 5(3): 437-454. https://doi.org/10.1142/s0219622006002040

[3] Suminar, J. R., Trisyani, M. (2012). Online course: media empowering in education process. Procedia - Social and Behavioral Sciences, 67(3): 203-207. https://doi.org/10. 1016/j.sbspro.2012.11.322

[4] Hamm, S., Robertson, I. (2010). Preferences for deep-surface learning: avocational ducation case study using a multimedia assessment activity. Australasian Journal of Educational Technology, 26(7): 951-965. https://doi.org/10.14742/ajet.1027

[5] Nesterov, A. A., Anan'Ev, V. N. (2004). An automated production line for generalpurpose lamp bulbs based on the ribbon technology. Glass and Ceramics, 61(7-8): 252254. https://doi.org/10.1023/b:glac.0000048357.57851.06

[6] Wong, Y. P., Othman, S., Lau, Y. L., Son, R., Chee, H. Y. (2017). Loop mediated isothermal amplification (lamp): a versatile technique for detection of microorganisms. Journal of Applied Microbiology, 124(3): 626-643. http://dx.doi.org/10.1079/9781780 641478.0059. https://doi.org/10.1111/jam.13647

[7] Carvalho, A., Areal, N., Silva, J. (2011). Students।" perceptions of blackboard and moodle in a portuguese university. British Journal of Educational Technology, 42(5): 824-841. https://doi.org/10.1111/j.1467-8535.2010.01097.x

[8] Yeou, M. (2016). An investigation of students' acceptance of moodle in a blended learning setting using technology acceptance model. Journal of Educational Technology Systems, 44(3): 300-318. https://doi.org/10.1177/0047239515618464 
[9] Zhou, Y. C., Meng, P. C. (2019). Diagnosis of causes for high railway traffic based on Bayesian network. Mathematical Modelling of Engineering Problems, 6(1), 136-140. https://doi.org/10.18280/mmep.060118

[10] Akbari, E., Karami, A. M., Ashjaee, M. (2018). Modeling the free convection in an open round cavity using a hybrid approach of Jaya optimization algorithm and neural network. International Journal of Heat and Technology, 36(3), 1061-1069. https://doi.org/10.18280/ ijht.360337

[11] Sánchez-Escalona, A. A., Góngora-Leyva, E. (2018). Artificial neural network modeling of hydrogen sulphide gas coolers ensuring extrapolation capability. Mathematical Modelling of Engineering Problems, 5(4), 348-356.https://doi.org/10.18280/mmep.050411

[12] Hua, J., He, L., Yan, K., Wang, M. (2019). Robotic slag offloading and process improvement of magnesium smelting in pidgeon process with faster region-based convolutional neural network. International Journal of Heat and Technology, 37(1), 345350. https://doi.org/10.18280/ijht.370141

[13] Mostefa, T., Tarak, B., Hachemi, G. (2018). An automatic diagnosis method for an open switch fault in unified power quality conditioner based on artificial neural network. Traitement du Signal, 35(1), 7-21. https://doi.org/10.3166/ts.35.7-21

[14] Bello, A. A., Mamman, M. B. (2018). Monthly rainfall prediction using artificial neural network: A case study of Kano, Nigeria. Environmental and Earth Sciences Research Journal, 5(2), 37-41. https://doi.org/10.18280/eesrj.050201

[15] Kumar, I., Sachan, V., Shankar, R., Mishra, R. K. (2018). An investigation of wireless SDF hybrid satellite terrestrial relaying network over time selective fading channel. Traitement du Signal, 35(2), 103-120. https://doi.org/10.3166/ts.35.130-120

[16] Neelapu, R., Devi, G. L., Rao, K. S. (2018). Deep learning based conventional neural network architecture for medical image classification. Traitement du Signal, 35(2), 169182. https://doi.org/10.3166/ts.35.169-182

[17] Yoshida, M. (2018). An investigation of the social network system competencies of high school students in Japan, International Journal of Emerging Technologies in Learning, 13(5): 4-18. https://doi.org/10.3991/ijet.v13i05.8101

[18] Walker, D., Livadas, L., Miles, G. (2011). Key influencing factors behind moodle adoption in irish small to medium sized higher education colleges. European Journal of Open, Distance and E-Learning, 9.

[19] Maciel, D. T., Soares, W., Amaral, E. (2009). Moodle platform for online tutoring during internships. Medical Education, 43(11): 1113-1114. https://doi.org/10.1111/j.13652923. 2009.03462.x

[20] Yue, W. S., Kaur, S. (2016). A survey of students' perceptions on online assessment in the modular object-oriented dynamic learning environment (moodle). Advanced Science Letters, 22(12):4082-4086. https://doi.org/10.1166/asl.2016.8210

[21] Castilho-Barilli, E., Freitas-Barretto, S., Moura-Lima, C., Antonio-Menezes, M. (2014). Assessment of the use of online communities to integrate educational processes development teams. Interactive Technology and Smart Education, 11(4): 270-286. https:// doi.org/10.1108/itse-09-2014-0029

[22] Beatty, B., Ulasewicz, C. (2006). Faculty perspectives on moving from blackboard to the moodle learning management system. TechTrends: Linking Research and Practice to Improve Learning, 50(4): 36-45. https://doi.org/10.1007/s11528-006-0036-y

[23] Mwalumbwe, I., Mtebe, J. S. (2017). Using learning analytics to predict students' performance in moodle learning management system: a case of mbeya university of science and technology. Electronic Journal of Information Systems in Developing Countries, 79(1): 1-13. https://doi.org/10.1002/j.1681-4835.2017.tb00577.x

\section{$6 \quad$ Authors}

Lina Wang has been pursuing this English teaching career since her graduation from the post graduate school. Thanks to her constant and consistent pursuit, she has developed a strong sense of affection for English language teaching and gained a wide 
range of recognition in Beijing Jiaotong University at Haibin College. Known for her productive communication and skilled instruction, she has formed her teaching style with a unique feature of interaction and inspiration, for she often ardently encourages students to share their creative and critical points of view in the process of language learning. As a result, she prepared quite hard and was honored the third place of Teaching Excellence Award in 2017. Moreover, in the following year, she won the third place in the 9th National Foreign Language Teaching Contest (Hebei Province, China. 2018). Besides teaching achievements, she also strives for better and further exploration in academic research on English language teaching approaches and English-Chinese translation theories. Therefore, several articles have been published in related journals. Progress of professional development in English language teaching promotes her to go further in this field.

Ruying Huang is an experienced and passionate teacher of English Language Teaching with more than one decade in Beijing Jiaotong University at Haibin College. She is deeply intrigued in teaching English as a second language and inspired by language teaching practice as a result of contributing productively to several journal articles focusing on English language teaching and English-Chinese translation. She has professionally designed and developed her teaching approaches through novel, innovative and interactive ways. Meanwhile, she explores and employs smart techniques in her classroom to encourage students to speak freely in public, rendering a comfortable environment for students to take every opportunity to practice English. Through enormous efforts and energy, she won the third place in the 7th National Foreign Language Teaching Contest (Hebei Province, China. 2016). In addition, she enjoys taking part in various language teaching workshops and seminars for a better communication in this field. In the long run, in order to stimulate creative and critical thinking in language learning process, she is willingly driven by the greater challenges and achievements from English language teaching and researching.

Article submitted 2019-04-13. Resubmitted 2019-06-27. Final acceptance 2019-07-02. Final version published as submitted by the authors 